\title{
The Level of Soluble FMS-Like Tyrosinkinase-1, Placental Growth Factor and Vitamin E in Pre-Eclampsia and Normotensive Pregnancy
}

\author{
John Wantania, Meilany Durry, Janno Bernadus \\ Faculty of Medicine, University of Sam Ratulangi, Manado, Indonesia \\ Email: john_w_og@yahoo.com
}

Received 17 May 2015; accepted 7 July 2015; published 10 July 2015

Copyright (C) 2015 by authors and Scientific Research Publishing Inc. This work is licensed under the Creative Commons Attribution International License (CC BY). http://creativecommons.org/licenses/by/4.0/

(c) (i) Open Access

\begin{abstract}
Background: This study aims to determine the differences of angiogenic markers sFit-1 (soluble FMS-like tyrosine kinase-1), Placental Growth Factor (PIGF) and antioxidant (vitamin E) levels in pre-eclampsia compared with normotensive pregnancies. Methods: In a cross-sectional study performed on 40 normotensive pregnancies and 40 pre-eclampsia women, serum levels of sFlt-1, PIGF and vitamin E were measured with ELISA methods. Statistical analysis used Mann Whitney. Results: The serum levels from the group of normotensive pregnancy and pre-eclampsia women consecutively are as follows: sFlt-1 $2251.32 \pm 416.17 \mathrm{pg} / \mathrm{mL}$ and $2950.78 \pm 221.34 \mathrm{pg} / \mathrm{mL}$, having a very significant difference $(p=0.00) ;$ PIGF $391.67 \pm 293.92 \mathrm{pg} / \mathrm{mL}$ and $150.15 \pm 105.34 \mathrm{pg} / \mathrm{mL}$, having a very significant difference; vitamin $E$ 8537.21 \pm 6299.74 unit and $700.61 \pm 233.70$ unit, having a very significant difference. Conclusion: There is a very significant difference between angiogenic markers and antioxidant levels in pre-eclampsia and normotensive pregnancies.
\end{abstract}

\section{Keywords}

sFlt-1, PIGF, Vitamin E, Pre-Eclampsia, Normotensive Pregnancies

\section{Introduction}

Pre-eclampsia has been an incompletely resolved obstetric problem. This disorder causes $5 \%-15 \%$ pregnancy difficulties and is one of the three most common causes of maternal and perinatal morbidity and mortality, as well as bleeding and infection [1]. The incidence of pre-eclampsia according to WHO (World Health Organiza- 
tion) is $0.5 \%$ of all pregnancies. It means that 700,000 cases of pre-eclampsia occur annually and 43,000 of them lead to mortality cases [1]-[4]. In Indonesia, the frequency of pre-eclampsia is approximately $3 \%-10 \%$ [5].

There have been many risks and protective factors related to pre-eclampsia. In general, the risk factors can be grouped as maternal factors (e.g. extreme age, parity, and history of pre-eclampsia), medical risk factors (e.g. chronic hypertension, diabetes mellitus or renal disease) and placental factors (e.g. hiperplasentosis, Gemelli, and gestational trophoblastic disease). Nevertheless, all these factors are entirely predisposing factors with unclear mechanisms [1] [2].

The potential predicting factors involved in pre-eclampsia can be explored by the discovery of some molecular pathways that regulate pseudo-vasculogenesis. These factors include the angiogenic factor and its receptor or anti-angiogenic factor. Latest studies found the existence of two anti-angiogenic proteins that were produced in excess in maternal circulation, and responsible for the phenotype of pre-eclampsia: soluble FMS-like tyrosinekinase-1 (sFlt-1 = sVEGFR1) and soluble Endoglin (sEng). Its pro-angiogenic factors consisting of Vascular Endothelial Growth Factor (VEGF), Placental Growth Factor (PlGF) and Transforming Growth Factor $\beta-1$ (TGF $\beta-1)$ [6] [7].

In pre-eclampsia, there are conditions of decreased production of enzymatic antioxidants and increased several markers of oxidative stress, as well. Unfortunately, supplementation with vitamin E is still controversial and has not been shown significantly beneficial [6].

The unclear relationship and differences between angiogenic markers and vitamin $\mathrm{E}$ as antioxidants in preeclampsia and normotensive pregnancies prompted us to conduct this research.

\section{Method}

A cross-sectional method was performed to measure the level of angiogenic markers, soluble FMS-like tyrosine kinase-1 (sFlt-1), and Placental Growth Factor (PIGF), and antioxidant (vitamin E) in 40 pre-eclampsia and 40 normotensive pregnant women (blood pressure equal or less than 120/80 mmHg) at Prof. Dr. R. D. Kandou Hospital, Manado from March to November 2011. This study was approved by the Medical Ethics Committee, Prof. Dr. R. D. Kandou Hospital Manado (DM.01.04/II.3/1196/2010).

Patients with pre-eclamptic pregnancy (blood pressure equal or more than 140/90 $\mathrm{mmHg}$ with proteinuria), more than 24 weeks of gestation, and receiving the standard pre-eclampsia therapy, as well as normotensive pregnancy as the control group, were recruited. Those with chronichypertention, history of pregnancy with DM, asthma, other obstetric problems and other chronic diseases, and those taking suplementation of vitamin E, were excluded.

Measurement of angiogenic marker levels (sFlt-1 and PlGF) and the levels of antioxidants (vitamin E) were done using techniques of enzyme-linked immunosorbent assay (ELISA). Comparisons of angiogenic markers and antioxidant level were analyzed by using Mann Whitney. Statistical significance was set at p value of $<0.05$. The data were analysed by SPSS v.14.

\section{Results}

Subjects were divided into two groups of 40 each. One group is pregnant women with normotensive blood pressure and the other group is pregnant women with pre-eclampsia.

The research results obtained can be seen in Table 1.

There was no statistical difference in age and parity between pre-eclampsia and normotensive group. It seems there was common tendency pre-eclampsia occurring in higher bodyweight and in non smoking group.

\subsection{Angiogenic Markers and Pre-Eclampsia}

The serum levels of sFlt-1 in normal pregnancy $(2251.32 \pm 416.17 \mathrm{pg} / \mathrm{mL})$ was significantly lower than that of pre-eclamptic pregnancy $(2950.78 \pm 221.34 \mathrm{pg} / \mathrm{mL}), \mathrm{p}=0.001$ (Figure 1).

Conversely, the serum levels of PlGF in normal pregnancy was significantly higher compared to pre-eclamptic woman (391.67 $\pm 293.92 \mathrm{pg} / \mathrm{mL}$ vs $150.15 \pm 105.34 \mathrm{pg} / \mathrm{mL}, \mathrm{p}=0.001)$ (Figure 2).

\subsection{Vitamin E and Pre-Eclampsia}

Levels of vitamin $\mathrm{E}$ in normotensive and pre-eclampsia are consecutively $8537.21 \pm 6299.74$ and $700.61 \pm$ 
Table 1. Characteristics of the sample.

\section{Age (years)}

$<20$

$31-35$

Parity

\section{Body Weight}

$61-80$

$81-100$

Smoking History

No

Passive

Active

Labor

Not in Labor

In Labor

\section{Gestational Age (Weeks)}

$$
<34
$$$$
34-<37
$$$$
37-40
$$$$
>40
$$

\section{Blood Pressure}

Normotensive
Mild Pre-Eclampsia
evere Pre-Eclampsia

$18 \quad 39$

21 0

$2-1$

$26 \quad 27$

14
1

2 2

$24 \quad 23$

$13-10$

$40 \quad 0$

$0 \quad 16$

$\begin{array}{ll}0 & 24\end{array}$

233.70 Unit, which have a very significant difference.

We observed the relationship between sFlt-1, PlGF and the levels of vitamin $\mathrm{E}$ in pre-eclampsia and revealed a very significant relation $(-0.729 ; \mathrm{p}<0.01)$ between sFlt-1 and vitamin $\mathrm{E}$; and a significant relation $(0.222$; $\mathrm{p}<$ 0.05) between PlGF and vitamin E (Figure 3).

\section{Discussion}

The angiogenic marker sFlt-1 is a VEGF receptor produced in abundance by cytotrophoblasts during trophoblast 


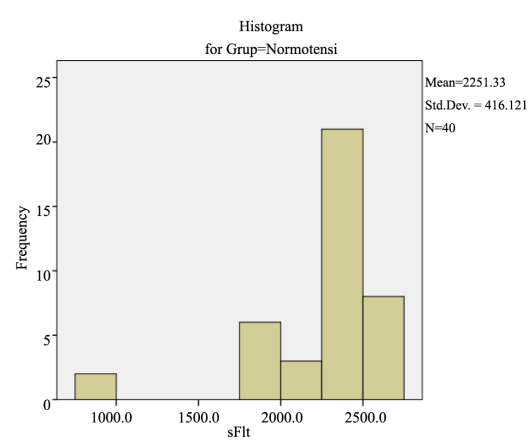

(a)

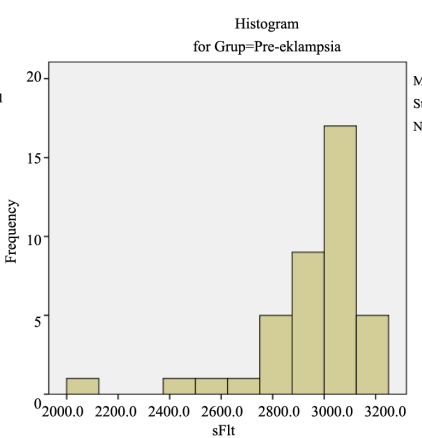

(b)

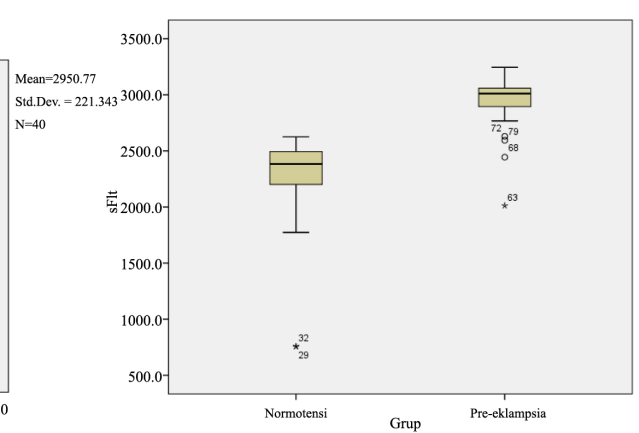

(c)

Figure 1. Shows the comparison of level sFlt-1 between normotensive and pre-eclampsia.

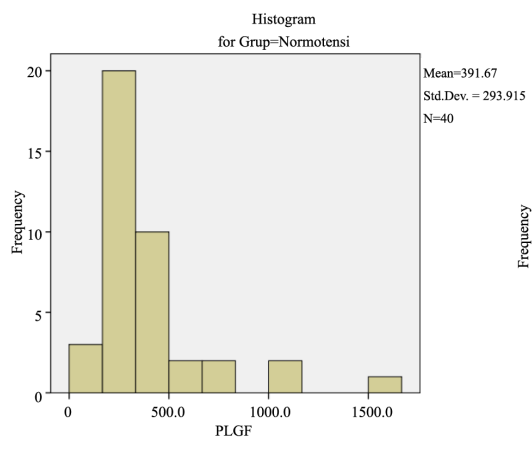

(a)

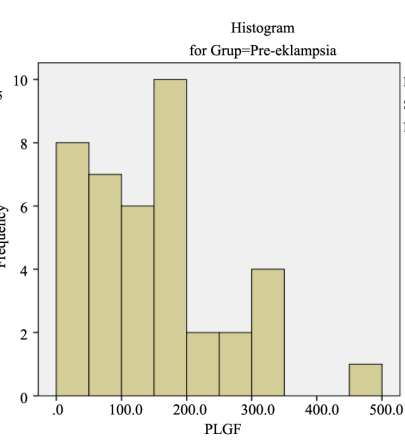

(b)

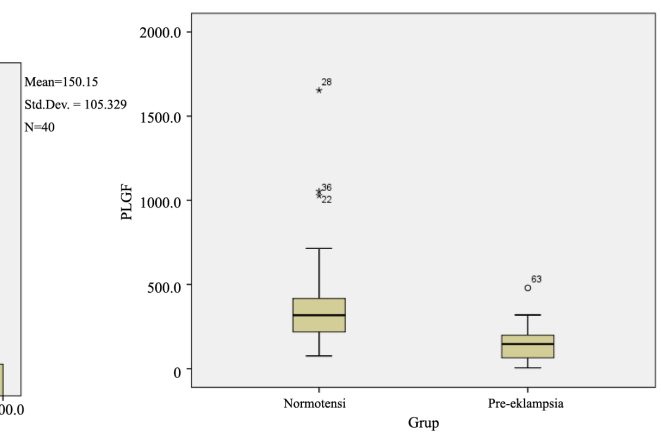

(c)

Figure 2. Shows the comparison of level PIGF between normotensive and pre-eclampsia.

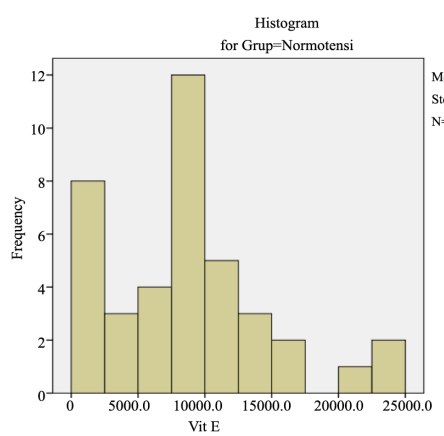

(a)

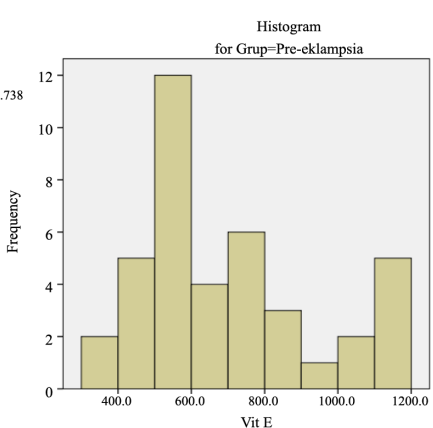

(b)

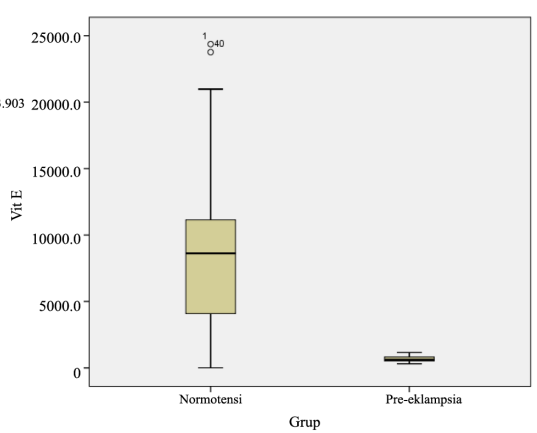

(c)

Figure 3. Shows the comparison of level vitamin E between normotensive and pre-eclampsia.

invasion to the surrounding tissues. The endogenous production of sFlt-1 released pieces of Flt-1 which is soluble and so-called soluble Flt-1 (sFlt-1) into the circulation. This soluble form losts its cytoplasmic and transmembrane domains but still had a ligand-binding domain. sFlt-1 serves as a feedback during development and prevents the binding of VEGF and KDR receptors [8].

This angiogenic factor seems to play an important role in the function and formation of vascularization during pregnancy which include maternal spiral arteries in the uterus to meet the perfusion of the placenta. sFlt- 1 binds to VEGF and PlGF, to compete in binding to receptors located in the endometrium and is associated with failure of vascular functions. Levine et al. reported a significant difference in angiogenic factors in pre-eclampsia which VEGF levels decreased when the concentration of sFlt-1 increased [9].

sFlt-1 levels that increased in the placenta and serum of pre-eclampsia patients was generally detected at the 5 th week before the onset of pre-eclampsia and decreased immediately after delivery. sFlt-1 levels were inversely related to gestational age [10] [11]. 
This study also found that levels of sFlt-1 and PlGF are inversely and highly significantly associated with the incidence of pre-eclampsia, although the level obtained in this study was slightly lower than other previous studies.

Levine and Noris also reported an increase in sFlt-1 in patients with pre-eclampsia. In Levine's study which involved 40 samples taken after the onset of pre-eclampsia, found 16 women with high (averaged of 5746 $\mathrm{pg} / \mathrm{mL}$ ) sFlt-1 levels and 24 with low level (averaging of $3007 \mathrm{pg} / \mathrm{mL}$ ) [9] [12].

Robinson et al. compared the levels of serum sFlt-1 and PlGF from 80 patients with mild pre-eclampsia and severe pre-eclampsia with 32 controls. PlGF decreased in pre-eclampsia patients than controls. sFLt1 increased in pre-eclamptic patients compared to controls. PlGF concentration was 3 times lower in patients with severe pre-eclampsia than in the mild pre-eclampsia. The sFlt-1 levels 1.5 times higher in severe than mild pre-eclampsia but not statistical significantly different. This difference was also not significant for severe pre-eclampsia and the HELLP (Hemolysis, Elevated Liver enzyme, Low platelets) syndrome [13].

The results obtained in this study are also in accordance with many previous studies which revealed that the serum levels of PIGF decreased in pre-eclampsia. The decreased levels of PIGF are due to the homolog structure of PIGF and VEGF so they can be bound with a large number of sFlt-1 serum that appears in pre-eclampsia. PIGF levels are inversely related to levels of sFlt-1 [6] [8] [14].

Some researchers found that the placenta in pre-eclampsia expresses exccesive levels of angiogenic factors sFlt-1 and mRNA ENG. The researchers then used these factors to induce pre-eclampsia in pregnant rats. This treatment led to changes in blood pressure, elevated liver enzymes and proteinuria in the rats [15] [16].

Baumann et al. also revealed the serum levels of sEng and sFlt-1 were higher in women who developed preeclampsia compared to controls (sEng $5.57 \pm 1.18 \mathrm{ng} / \mathrm{mL}$ vs. $5.02 \pm 1.01 \mathrm{ng} / \mathrm{mL}, \mathrm{P}=0.009$; sFlt-1 $1764 \pm 757$ $\mathrm{pg} / \mathrm{mL}$ vs $1537 \pm 812 \mathrm{pg} / \mathrm{mL}, \mathrm{P}=0.036$ ), in which the sensitivity and specificity for predicting pre-eclampsia were $63 \%$ and $57 \%$ for sEng and $64 \%$ and $56 \%$ for sFlt-1 [7]. Ohkuchi, et al. also showed that the earlier the onset of pre-eclampsia, the greater the decrease in PlGF [17].

According to Lam et al., pre-eclampsia does not develop in all women with high sFlt-1 or low PlGF, but can occur in low sFlt-1 and high PlGF levels, with unexplained mechanism. They suspected that the increase of this soluble factor is the result of placental hypoxia [14].

Several studies have shown that pre-eclamptic placenta produces large amounts of superoxide and is accompanied by decreased levels of antioxidants such as vitamin E and antioxidant enzymes activities. In this study, levels of vitamin E decreased significantly. On the other hand, the condition of placental hypoxia and oxidative stress increases the production of prostaglandins and lipid peroxidation. Lipid peroxides are formed when free radicals interact with polyunsaturated fatty acids in cell membranes. Excessive lipid peroxidation required large amounts of antioxidants to neutralize the free radicals formed this process, and resulted in lower serum concentrations of antioxidants such as vitamin $\mathrm{E}$ which is a fat-soluble antioxidant. Vitamin $\mathrm{E}$ is considered the most appropriate antioxidant to prevent free radical formation from lipid oxidation. This explains why the levels of vitamin $\mathrm{E}$ in pre-eclampsia decreased. However, not all studies can prove this with decreased levels of vitamin E. Decreased levels of vitamin E are more frequently found in cases of severe pre-eclampsia. Based on this, some studies have tried to provide supplementation of vitamin $\mathrm{E}$ to prevent the occurrence of placental oxidative stress which is expected to reduce the risk of pre-eclampsia, though the results of many studies are still controversial [18] [19].

The pathogenesis of pre-eclampsia involves several processes. In-adequate trophoblast invasion leads to defects in spiral arteries remodeling resulting in imperfect oxygen placental perfusion. Theoretically, the defect of oxygen perfusion in placenta causes placental tissue hypoxia which produces one of the HIF transcription factors and sFlt- 1 in response to the hypoxic condition. The results of this study indicate that the strongest single marker associated with the incidence of pre-eclampsia is sFlt-1, and the best combination is sFlt-1, and Vitamin $\mathrm{E}(\mathrm{r}=-0.729$; $\mathrm{p}<0.01)$, compared with PlGF with vitamin $\mathrm{E}(\mathrm{r}=0.222 ; \mathrm{p}<0.05)$. In general, we obtained the relationship between angiogenic markers with Vitamin E [20].

Elevated levels of sFlt receptor-1 will bind to a large number of free VEGF and PIGF which is required in the process of placental angiogenesis. PlGF levels were detected in patients with pre-eclampsia decreasesing inversely with levels of sFlt-1. Hypoxia also causes the state of oxidative stress accompanied with the release of various pro-inflammatory and pro-proliferative cytokines and reactive oxygen species (ROS) free radicals which could be offset by the defense mechanism of antioxidants (such as vitamin E) in in-adequate or excessive response. This reaction in turn causes endothelial injury and dysfunction that evokes a variety of inflammatory 
responses and continues from the onset of maternal symptoms of pre-eclampsia [21].

The combination of angiogenic marker levels of sFlt-1 and the antioxidant vitamin $\mathrm{E}$ in this study has significant relationship with the incidence of pre-eclampsia. This can be explained by the theory of hypoxia/reperfusion and oxidative stress which is compensated with a defense mechanism against oxidative stress by using antioxidants [22].

Finally, biological markers that have a very strong relationship with pre-eclampsia have a great opportunity to be developed into predictive factors through further research so that the incidence of pre-eclampsia can be detected as early as possible and can receive the interventions to anticipate or even prevent the complications.

The limitation of this study only using one antioxidant (vitamin E), whereas many antioxidants may involved in pre-eclampsia patomechanism. The design of this study (cross sectional study) only revealed the final result of all the markers in the late pregnancy.

\section{Conclusion}

In conclusion, there is a very significant difference between levels of angiogenic markers (sFlt-1, PlGF) and levels of antioxidants (vitamin E) in pre-eclampsia and normotensive pregnant women. There is a relationship between levels of angiogenic markers with higher levels of antioxidants (vitamin E). The marker that has the strongest relationship with the incidence of pre-eclampsia is sFlt1 and the combination of markers that have the strongest relationship is between sFlt-1 and vitamin E.

\section{Acknowledgements}

Dr. Trihono, MSc and all the mentors from Research and Development Division of Indonesian Ministry of Health for the research grant.

\section{References}

[1] Cunningham, F.G., Leveno, K.J., Bloom, S.L., Hauth, J.C., Rouse, D.J. and Spong, C.Y., Eds. (2014) Williams Obstetrics. 24th Edition, McGraw Hill, New York.

[2] Wagner, L.K. (2004) Diagnosis and Management of Pre-Eclampsia. American Family Physician, 70, 2317-2324.

[3] Emery, P.S. (2005) Hypertensive Disorders of Pregnancy: Overdiagnosis Is Appropriate. Cleveland Clinic Journal of Medicine, 72, 345-352. http://dx.doi.org/10.3949/ccjm.72.4.345

[4] Barton, J.R. and Sibai, B.M. (2007) Pre-Eclampsia. In: Manual of Obstetrics, 7th Edition, Lippincott Williams \& Wilkins, Texas.

[5] Alkaff, T.R., Hartini, T.N.S. and Hakimi, M. (2008) The Correlation between Seasonal Variation and Pre-Eclampsia in Dr. Sardjito Hospital, Yogyakarta, 1999-2003. Majalah Obstet Ginekol Indones, 32, 139-142.

[6] Wang, A., Rana, S. and Karumanchi, S.A. (2009) Pre-Eclampsia: The Role of Angiogenic Factors in Its Pathogenesis. Physiology, 24, 147-158. http://dx.doi.org/10.1152/physiol.00043.2008

[7] Baumann, M.U., Bersinger, N.A., Mohaupt, M.G., Raio, L., Gerber, S. and Surbek, D.V. (2008) First-Trimester Serum Levels of Soluble Endoglin and Soluble FMS-Like Tyrosine Kinase-1 as First-Trimester Markers for Late-Onset Pre-Eclampsia. American Journal of Obstetrics Gynecology, 199, 266.e1-266.e6. http://dx.doi.org/10.1016/j.ajog.2008.06.069

[8] Davidson, J.M., Homuth, V., Jeyabalan, A., Conrad, K.P., Karumanchi, S.A., Quagging, S., et al. (2004) New Aspect in the Pathophysiology of Pre-Eclampsia. Journal of the American Society of Nephrology, 15, 2440-2448. http://dx.doi.org/10.1097/01.ASN.0000135975.90889.60

[9] Levine, R.J., Qian, C., Maynard, S.E., Yu, K.F., Epstein, F.H. and Karumanchi, S.A. (2006) Serum sFlt1 Concentration during Pre-Eclampsia and Mid Trimester Blood Pressure in Healthy Nulliparous Women. American Journal of Obstetrics Gynecology, 194, 1034-1041. http://dx.doi.org/10.1016/j.ajog.2005.10.192

[10] Stepan, H. (2009) Angiogenic Factors and Pre-Eclampsia: An Early Marker Is Needed. Clinical Science (London), 116, 231-232. http://dx.doi.org/10.1042/CS20080598

[11] Dechend, R. and Luft, F. (2008) Angiogenesis Factors and Preeclampsia. Nature Medicine, 14, 1187-1188. http://dx.doi.org/10.1038/nm1108-1187

[12] Noris, M., Perico, M. and Remuzzi, G. (2005) Mechanism of Disease: Pre-Eclampsia. Nature Clinical Practice Nephrology, 1, 98-114. http://dx.doi.org/10.1038/ncpneph0035

[13] Robinson, C.J., Johnson, D.D., Chang, E.Y., Armstrong, D.M. and Wang, W. (2006) Evaluation of Placenta Growth 
Factor and Soluble Fms-Like Tyrosine Kinase 1 Receptor Levels in Mild and Severe Preeclampsia. American Journal of Obstetrics and Gynecology, 195, 255-259. http://dx.doi.org/10.1016/j.ajog.2005.12.049

[14] Lam, C., Lim, K. and Karumanchi, S.A. (2005) Circulating Angiogenic Factors in the Pathogenesis and Prediction of Preeclampsia. Hypertension, 46, 1077-1085. http://dx.doi.org/10.1161/01.HYP.0000187899.34379.b0

[15] Rana, S., Karumanchi, S.A., Levine, R.J., Venkatesha, S., Sakti, H.J.A., Tarnez, H., et al. (2007) Sequential Changes in Antiangiogenic Factors in Early Pregnancy and Risk of Developing Preeclampsia. Hypertension, 50, 137-142. http://dx.doi.org/10.1161/HYPERTENSIONAHA.107.087700

[16] Lindheimer, M.D. and Romero, R. (2007) Emerging Roles of Antiangiogenic and Angiogenic Proteins in the Pathogenesis and Prediction of Preeclampsia. Hypertension, 50, 35-36. http://dx.doi.org/10.1161/HYPERTENSIONAHA.107.089045

[17] Ohkuchi, A., Hirashima, C., Matsunara, S., Suzuki, H., Takahashi, H., Arai, F., et al. (2007) Alterations in Placental Growth Factor Levels before and after the Onset of Preeclampsia are More Pronounced in Women with Early-Onset Severe Preeclampsia. Hypertension Research, 30, 151-159. http://dx.doi.org/10.1291/hypres.30.151

[18] Rumbold, A. and Crowther, C.A. (2010) Vitamin E Supplementation in Pregnancy (Review). The Cochrane Library.

[19] Rumbold, A., Crowther, C., Haslam, R., Dekker, G. and Robinson, J. (2006) Vitamins C and E and the Risks of Preeclampsia and Perinatal Complications. The New England Journal of Medicine, 354, 1796-1806. http://dx.doi.org/10.1056/NEJMoa054186

[20] Zagorska, A. and Dulak, J. (2004) HIF-1: The Known and Unknown of Hypoxia Sensing. Acta Biochimica Polonica, 51, 563-578.

[21] Welch, P., Amankwah, K.S., Miller, P., McAsey, M.E. and Torry, D. (2006) Correlations of Placental Perfusion and PlGF Protein Expression in Early Human Pregnancy. American Journal of Obstetrics and Gynecology, 194, 1625-1629. http://dx.doi.org/10.1016/j.ajog.2006.01.012

[22] Lazar, L. (2012) The Role of Oxidative Stress in Female Reproduction and Pregnancy. In: Lushchak, V., Ed., Oxidative Stress and Diseases, In Tech, 313-336. 